\title{
Trabalho e Religião: questões éticas que permeiam as atividades dos membros da Comunidade de Confissão Luterana Nova Esperança em Rio Grande-RS
}

\section{Débora Laís Freitas*}

dl.freitas@live.com

\begin{abstract}
Resumo
O presente artigo procura analisar a relação entre os membros de descendência alemã da comunidade Luterana Nova Esperança, na periferia da cidade do Rio Grande-RS e a atividade comerciária na cidade. Esta pesquisa se justifica na observação empírica de que boa parte dos membros da Nova Esperança trabalha no setor do comercio, em feiras ou pequenos estabelecimentos, além do fato de que a comunidade foi criada para abrigar fieis trabalhadores das feiras que não conseguiam participar dos cultos realizados na comunidade São Miguel, no centro da cidade. Para tanto, refletimos sobre as condições da imigração alemã para o Rio Grande do Sul e as concepções sobre o trabalho na doutrina luterana, buscando um paralelo entre o contexto histórico e social vivenciado pelos descendentes de alemães da comunidade em questão e os aspectos que regem a conduta do protestante luterano em sua vida, através de leituras sobre o tema e recurso de questionários e entrevistas com membros da comunidade.
\end{abstract}

\section{Palavras-chaves}

Igreja Luterana; trabalho; Max Weber

Work and Religion: Ethical issues that permeate the activities of members of the Nova Esperança Lutheran Confession Community in Rio Grande - RS

\begin{abstract}
This article tries to analyze the relationship between the members of German descent of the Lutheran community Nova Esperança, in the outskirts of the city of Rio Grande-RS and the commercial activity in the city. This research is justified by the empirical observation that most members of Nova Esperança work in the trade sector at fairs or small establishments, in addition to the fact that the community was created to house faithful workers at fairs who could not participate in the celebrated cults In the São Miguel community, in the center of the city. To do so, we reflect on the conditions of German immigration to Rio Grande do Sul and the conceptions about work in the Lutheran doctrine, seeking a parallel between the historical and social context experienced by the descendants of Germans of the community in question and the aspects that govern the conduct of the Lutheran Protestant in his life, through lectures on the topic and resource of questionnaires and interviews with community members.
\end{abstract}

\section{Keywords}

Lutheran Church; work; Max Weber 


\section{Introdução}

A cidade do Rio Grande é a mais antiga do estado do Rio Grande do Sul, colonizada primeiramente por portugueses. Sua posição geográfica estratégica na defesa dos territórios gaúcho e brasileiro contra os espanhóis e o seu potencial portuário (como centro comercial) estimulou a vinda de imigrantes de outras etnias europeias (poloneses, italianos, alemães, etc.) que, a princípio, se haviam concentrado nas regiões norte e central do estado.

Ao longo da história, muitos foram os contextos que influenciaram a vinda e estabelecimento das populações de diferentes nacionalidades para trabalhar em Rio Grande, o que nos coloca atualmente em uma realidade social de multiculturalidade, que é refletida material e simbolicamente na estrutura da cidade.

Tendo em vista o contexto da cidade, construída a partir da colonização de diferentes etnias, surgiu o interesse de analisar mais profundamente a atuação alemã na cidade, tendo em vista que muitos dos descendentes dessa etnia são trabalhadores do comércio e da agricultura, que tomam as ruas da cidade nas feiras, e parte deles ligados à religião Protestante Luterana. Com sede municipal na Rua Barão de Cotegipe, a Igreja Evangélica de Confissão Luterana no Brasil reúne entre os seus fiéis muitos trabalhadores do comércio e feiras.

A paróquia em Rio Grande se divide nas comunidades São Miguel, no centro da cidade, e Nova Esperança, localizada na Vila Eulália (ou "Prado"), fundada para atender justamente à demanda dos fiéis moradores das zonas periféricas que trabalhavam nas feiras pela manhã e não conseguiam acompanhar os horários dos cultos na região central. Nessa perspectiva, pretende-se discutir a relação entre a atividade comerciária e a religião luterana, especificamente dos fieis membros da Comunidade Nova Esperança.
Considerando-se essas observações, se faz importante analisar algumas características da comunidade, em especial, aspectos da doutrina religiosa que a cerca, e ainda hoje marcam a rotina da cidade e muitos de seus traços patrimoniais, como as feiras de agricultura da cidade, que têm seus comerciantes em sua maioria descendentes de alemães, e o comércio de um modo geral também constata a presença dessa etnia, mostrando que essa comunidade influencia a dinâmica social da cidade, e é influenciada pela sua estrutura.

Para que seja possível compreender porque a atividade comerciária se apresenta forte entre os fiéis da Comunidade Nova Esperança, é interessante compreendermos de que maneira esses traços culturais religiosos se consolidaram na comunidade de descendência alemã local e quais as adaptações que foram necessárias para a manutenção e preservação da cultura alemã e protestante entre os descendentes em questão.

A principal ferramenta de pesquisa é o levantamento de informações da população-foco (membros da comunidade Nova Esperança), a fim de obter dados que forneçam embasamento para a discussão das causas que culminam no perfil de atuação produtiva dos fiéis na cidade do Rio Grande. Para tanto, a primeira ferramenta de pesquisa utilizada foi um questionário aplicado a doze membros da Nova Esperança, considerando sua assiduidade nos eventos e cultos da mesma, a fim de analisar suas origens, formação e ocupação atual.

Após a tabulação dos dados dos questionários, e a verificação apresentada posteriormente neste artigo em relação à ocupação econômica no comércio por uma quantidade relevante dos sujeitos pesquisados, buscamos outras metodologias que possibilitassem uma maior inserção nas experiências de vida dos membros da comunidade.

Nesse sentido, a fonte primária da análise é baseada na importância da História Oral no processo de 
percepção do sujeito sobre sua atuação e a construção social do sentido de comunidade e sua relação com a vida econômica. Meihy $(2011$, p.55) indica que na análise da constituição de uma comunidade a partir da história oral, o diálogo e as entrevistas com membros permitem dar vida à instituição. Dessa forma, o uso de testemunhos de membros mais antigos da comunidade, bem como do pastor que ministra na mesma, é relevante para entendermos como esses sujeitos compreendem sua história e como ela reflete em suas atividades.

Do ponto de vista da representatividade, o testemunho individual é relevante para percebermos que aspectos são compartilhados pelos grupos sociais e que contribuíram para o seu sentido. No caso da comunidade em questão, as memórias trazidas nos relatos orais contribuem para a análise das condições sóciohistóricas que influenciaram na origem e construção social em torno do trabalho e da religião.

Sobre essa perspectiva, a intenção é buscar na memória dos sujeitos membros da comunidade Nova Esperança como se deu a organização urbana do núcleo de descendência alemã em Rio Grande, a partir de suas experiências no processo de consolidação das colônias da metade sul (especificamente interior de Pelotas e Canguçu, cidades de origem da maioria dos membros), o processo de transição da atividade agrária, nas colônias do interior do sul do Rio Grande do Sul, para a dinâmica urbana, a atividade comerciária na cidade do Rio Grande e sua relação com a religião.

. Nesse intuito, foram selecionadas duas senhoras que participaram da fundação da Comunidade Nova Esperança para falar em entrevista gravada e transcrita sobre o processo e a relação com a religião, na busca de uma melhor compreensão sobre a importância da religião na vida e atividades dos descendentes alemães que são foco da pesquisa.
O constante diálogo com a população descendente alemã se fez importante, pois se percebeu que as considerações trazidas pelos trabalhadores comerciais e praticantes do Luteranismo evidenciam o vínculo entre as tradições religiosas com a maneira de situar-se e atuar na sociedade rio-grandina, onde as diferentes famílias de descendência alemã mantêm vínculos que marcam o espaço da cidade: nas manifestações religiosas, no legado material e imaterial da cultura alemã, na estrutura econômica da cidade (qual rio-grandino nunca fez compras em feiras que tomam as ruas da cidade em vários dias da semana, em que grande parte dos produtores e fornecedores são de descendência alemã?).

Ainda considerando a importância da análise de fontes advindas da história oral, realizamos entrevista gravada e transcrita com o pastor luterano Rubem Bonato, que atua nas duas comunidades (São Miguel e Nova Esperança), a fim de coletar informações sobre a conduta luterana e fatores presentes na história dos membros da comunidade Nova Esperança que possam explicar a tendência ao comércio. Ainda, entrevistamos a presidenta da comunidade Nova Esperança, Leda Wally Virissimo com o intuito de levantar informações mais detalhadas sobre a consolidação da comunidade no espaço rio-grandino.

Tendo-se observado através de dados obtidos pelos questionários a relação entre a comunidade religiosa e o trabalho no comércio, é inevitável que não nos remetamos aos estudos sociológicos de Max Weber, que analisam as transformações da doutrina protestante na sociedade capitalista. Tendo em vista o extenso estudo de Weber sobre as religiões protestantes na consolidação do capitalismo comercial no século XVI, e a relação dos membros da comunidade Nova Esperança com o comércio, faz-se interessante realizar um paralelo entre aspectos trazidos na obra do autor e o contexto brasileiro experienciado pelos fiéis em questão desde o 
início do século XX até o início do século XXI, a fim de identificar semelhanças e divergências de percepções sobre a função da religião no contexto produtivo.

\section{Imigração Alemã}

Para compreendermos a relação dos membros da Comunidade Nova Esperança com o trabalho, faz-se necessário contextualizar as condições de imigração e o estabelecimento destes alemães e descendentes no espaço brasileiro, mais especificamente no interior do Rio Grande do Sul. Desse modo, cabe apresentarmos um resumo histórico de trabalhos de análise dessa constituição no território para, mais adiante, relacionarmos essas peculiaridades com a questão da religiosidade e a atividade no comércio.

HEINZ (2010) traz algumas considerações importantes acerca dos primeiros ciclos migratórios da Alemanha para o Brasil, que cumpriram ao longo da história diferentes funções. Nos primeiros movimentos de europeus não-portugueses para o Brasil, o sistema produtivo era escravista, e o objetivo do incentivo pela vinda de imigrantes desde o I Reinado (1824-1831), praticado pelo Major Georg Von Schaeffer a serviço do interesse imperial brasileiro, era basicamente o "branqueamento" da sociedade brasileira, introduzir traços da cultura europeia no país que, como consequência inevitável da escravidão, estava abarcando características da população negra em sua sociedade. A concepção do branqueamento pode ser observada na escrita de muitos homens de relevância à época, como salienta Silva (2007):

A ideologia do branqueamento foi defendida por homens como Joaquim Nabuco, Rui Barbosa e Euclides da Cunha, entre outros. Todos eles eram contrários á escravidão, mas imbuídos do racismo e da inferioridade inata dos negros. Na obra o Abolicionismo Joaquim Nabuco dá uma explicação para o que se pretendia ao abolir a escravidão: "absorver o sangue caucásico vivaz, enérgico e sadio que certamente embranqueceria o nosso povo" (CHIAVENATO, 1986 apud SILVA, 2007, p 95)

Nesse sentido, as primeiras ondas de colonização alemã no Brasil foram promovidas pelos interesses da elite em manter seu poder cultural e da força.

Os próximos movimentos migratórios foram conduzidos pela substituição da mão de obra escrava, e estimulado pelo Estado Brasileiro, que ofereciam terras e infraestrutura para os imigrantes que vinham estabelecer-se trabalhar no território brasileiro.

\section{Toda a politica imigrantista era dirigida no sentido de buscar no trabalhador branco europeu a redefinição do ato do trabalho e a concepção do trabalho como essência da construção do progresso da Nação. O siste- ma escravista e a sua expressão - o escravo - eram sempre colocados como os opositores ao progresso, como representantes do atraso da Nação (SALLES, 1986, p. 109).}

Tal intencionalidade explicitada corrobora com a análise posterior dada à relação observada entre os membros da Comunidade Nova Esperança com o trabalho e a religião, sendo esta a base ideológica para a dedicação e a permanência do sentido de comunidade essencial à atuação econômica.

Entretanto, a chegada e consolidação dos imigrantes alemães no território nacional não transcorreram de forma tranquila e garantida. Especificamente no Rio Grande do Sul, Vital Junior (2008) salienta que a vinda de imigrantes alemães também servia para povoar e tornar produtivas áreas que não eram de interesse ou propriedade dos grandes latifundiários, e com isso contribuir com a produção agrícola nos núcleos urbanos e promover a valorização fundiária da terra, pois os colonos recebiam as terras sem base de cultivo e necessitavam desmatá-las (principalmente pela prática das queimadas) para torná-las áreas produtivas, e isso agregava interesse ao mercado. 
Os imigrantes tiveram de lidar com os conflitos com povos indígenas, que não foram considerados no projeto de valorização fundiária; a infraestrutura prometida também teve de ser improvisada pelos colonos, que abriam estradas e construíam pontes de acesso, na tentativa de amenizar o isolamento e as dificuldades de movimentação tanto de produtos agrícolas quanto de pessoas que necessitavam de atendimento médico e outras necessidades básicas.

Vital Junior (2011) salienta, ainda, que "essa situação de isolamento era mais agravada entre colonos luteranos do que entre católicos" (p. 168), o que pode nos evidenciar um afastamento de cunho religioso entre as relações econômicas e sociais das comunidades. Essa falta de políticas públicas e valorização dos espaços ocupados pelos imigrantes nos evidenciam que, na verdade, o Império estava submetido aos interesses dos grandes latifundiários, que não sentiam o estabelecimento dos colonos como um acréscimo no desenvolvimento do mercado agrícola, mas sim como ameaça ao seu domínio sobre o espaço agrário e social.

O pastor da Paróquia da Igreja Evangélica de Confissão Luterana no Brasil em Rio Grande, Ruben Bonato, em entrevista, argumenta que além desses problemas territoriais encontrados na chegada, nenhuma forma de manifestação pela religião protestante era legitimada pelo Estado até 1863. Nesse sentido, todos os registros de casamentos e nascimentos eram feitos em igrejas católicas, o que, além de reforçar o sentimento de isolamento dos alemães e descendentes de origem protestante luterana, priva essas comunidades de manter um registro histórico de seus rituais e manifestações de fé.

Neste processo de isolamento que os imigrantes alemães vivenciavam nos espaços destinados a eles, os colonos acabaram por fortalecer seus laços em suas comunidades fechadas, a fim de preservar suas convic- ções e desenvolver seu próprio mercado interno, diversificando o plantio (a policultura) e reforçando sua existência como comunidade (SALAMONI, 2001, p. 32). Essa unificação se refletia principalmente nas instituições da escola, da família e da igreja, espaços do encontro entre seus princípios e sua realidade.

\section{A comunidade Nova Esperança}

Depois de traçar um histórico breve sobre a vinda dos alemães para o Rio Grande do Sul e constatar as dificuldades encontradas na chegada que favoreceram a união dos imigrantes e seus descendentes em torno da religião como forma de afirmação, cabe destacarmos algumas peculiaridades do Luteranismo no Brasil. Tais considerações são baseadas nas informações obtidas na entrevista com o pastor das comunidades luteranas do Rio Grande, o pastor Ruben Bonato, e também com a presidente da Comunidade Nova Esperança, Leda Wally. Tais relatos são relevantes para observarmos os elementos de caráter sócio-histórico que contribuem para o entendimento dos membros como comunidade a partir da perspectiva interna. Além disso, faz-se interessante abordar algumas considerações feitas por René Gertz (2001) no artigo “Os luteranos no Brasil”, publicado em 2001 na Revista de História Regional da Universidade Federal de Ponta Grossa (UFPG).

De acordo com o pastor Bonato, as igrejas luteranas no Brasil são divididas entre as Igrejas Livres ou Independentes, a Igreja Evangélica Luterana do Brasil (IELB) e a Igreja Evangélica de Confissão Luterana no Brasil (IECLB). As Igrejas Livres eram características das colônias, onde as comunidades eram compostas de igreja, cemitério e escola e, segundo as palavras do pastor, eram fundadas de acordo com a relação social estabelecida na região: o pastor também exercia a função de professor da escola, e se parte da comunidade não estivesse contente com o transcorrer das atividades, se 
concentravam em outro centro religioso - com igreja, cemitério e escola diferentes. Essa denominação se concentra mais no passado, quando as zonas rurais eram mais independentes da dinâmica urbana e globalizada, situação que acabava por reunir fiéis em menos vertentes mais consolidadas

Dessa maneira, podemos considerar as igrejas luteranas mais concentradas na IELB e na IELCB. O pastor Bonato nos afirma que a IELB (Igreja Evangélica Luterana do Brasil) é uma denominação que surge com a necessidade da vinda de pastores luteranos para as comunidades. De acordo com Gertz (2001, p. 13), esses missionários vinham com a perspectiva de acolher a sociedade de um modo geral, sem direcionar sua atuação aos descendentes alemães. Dentre alguns aspectos levantados por Gertz, deve-se citar que a IELB é mantenedora da Universidade Luterana do Brasil (ULBRA) e que, mesmo não priorizando as tradições alemãs na expressão de sua religiosidade, 612 dos 691 pastores listados pelo site oficial da IELB tem sobrenome de origem alemã (GERTZ, 2001, p. 14).

A Comunidade Evangélica de Confisssão Luterana Nova Esperança faz parte da Igreja Evangélica de Confissão Luterana no Brasil (IECLB). A IECLB é, segundo Gertz (2001, p. 10) o maior segmento luterano no Brasil, e sua direção "pode-se caracterizar, provavelmente, como "progressista": ela destaca os compromissos sociais e políticos da igreja, assumindo uma posição intermediária e de intermediação" (2001, p. 21). Sobre essa consideração, pode-se relatar que, por exemplo, a IECLB hoje já conta com um número expressivo de pastoras mulheres, inclusive a segunda vice-presidente nacional é a pastora Silvia Beatrice Genz. Em relação às instituições gestadas pela IECLB, cita-se a Escola
Superior de Teologia da IECLB em São Leopoldo, que forneceu o primeiro curso de pós-graduação em Teologia reconhecido pela CAPES. ${ }^{1}$

Para elucidar como se organiza a administração da IECLB, reproduzimos aqui o esquema disponível no Portal Luterano:

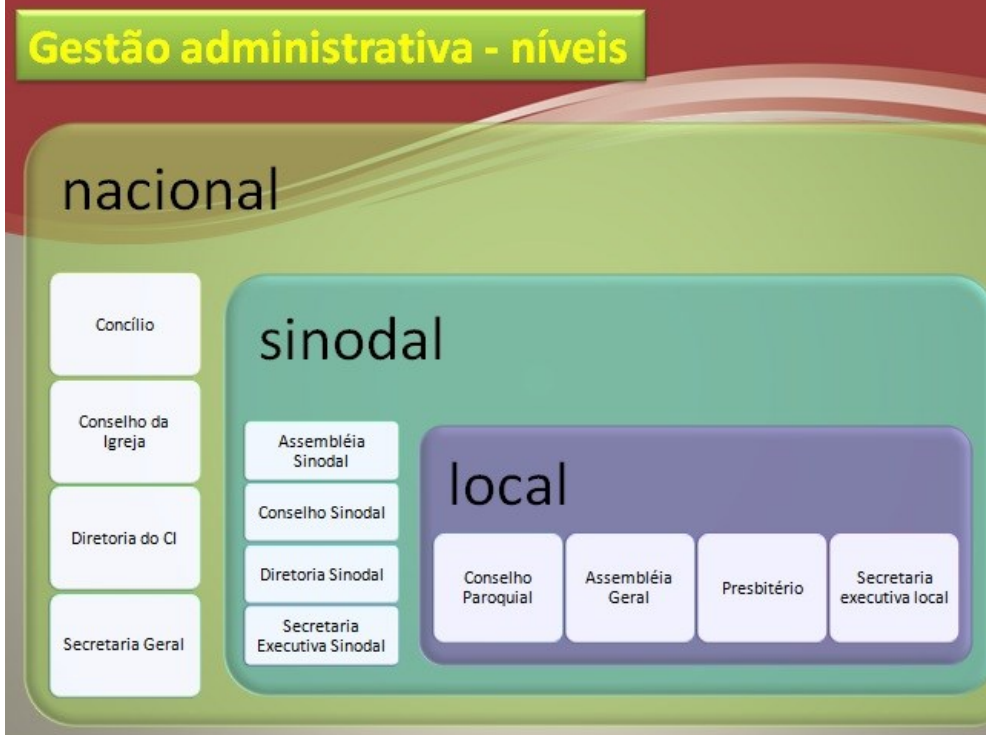

Fonte: Portal Luterano <www.luteranos.com.br $>$

Temos a gestão nacional, a sinodal (a nível regional) e a local. Na gestão local, temos o Conselho Paroquial que administra as comunidades (no caso do Rio Grande, São Miguel e Nova Esperança) e direciona as ações destas e do pastor responsável. Nas comunidades são eleitos os Presbitérios, cujos membros participam da administração e gestão das atividades e recurso da comunidade.

Como previamente mencionado no texto introdutório, a Comunidade Nova Esperança foi criada, segundo a presidente Leda e o pastor Bonato, com o intuito de reunir os fiéis de descendência alemã que moravam nas zonas periféricas da cidade do Rio Grande que, devido sua atividade produtiva ser predominantemente o comércio nas feiras, tinham dificuldade de frequentar a Comunidade Luterana São Miguel, no centro da cidade e com

${ }^{1}$ Coordenação de Aperfeiçoamento de Pessoal de Nível Superior (Capes), fundação do Ministério da Educação (MEC), desempenha papel fundamental na expansão e consolidação da pós-graduação stricto sensu (mestrado e doutorado) em todos os estados da Federação. 
cultos realizados pela manhã. Nesse sentido, em 1994, o pastor à época, Jorge Schieferdecker ${ }^{2}$, em consonância com os interesses dos fiéis, decidiu dividir a Paróquia nas comunidades São Miguel e Nova Esperança.

Criou-se uma diretoria nessa divisão, com membros ligados à Paróquia. De acordo com documento oficial do registro da comunidade, esta possui como órgãos a Assembléia Geral, o Presbitério, a Diretoria e o Conselho Fiscal. O documento ainda dispõe das funções dos membros e das eleições para o Presbitério e, ainda, sobre as incumbências da comunidade e seus membros que serão posteriormente consideradas.

Sobre as atividades exercidas diretamente no âmbito da Comunidade Nova Esperança, destacamos almoço e bingo organizados mensalmente pelos membros da comunidade, a fim de arrecadar recursos financeiros para a manutenção das atividades e o salão da sede é alugado para eventos particulares. Nos estatuto da comunidade, salienta-se como função dos membros da comunidade "contribuir financeiramente para a manutenção da Comunidade e dos demais órgãos e instâncias da Igreja, tais como a Paróquia, o Sínodo e a IECLB, na forma estabelecida pelo Presbitério e pelo Conselho Paroquial".

Em questionário aplicado a doze membros da comunidade, utilizando como critério a assiduidade nos eventos e cultos, se destaca como atividade econômica exercida pelos membros o comércio em feiras ou pequenos estabelecimentos $(75 \%)$, como mostra o gráfico a seguir:

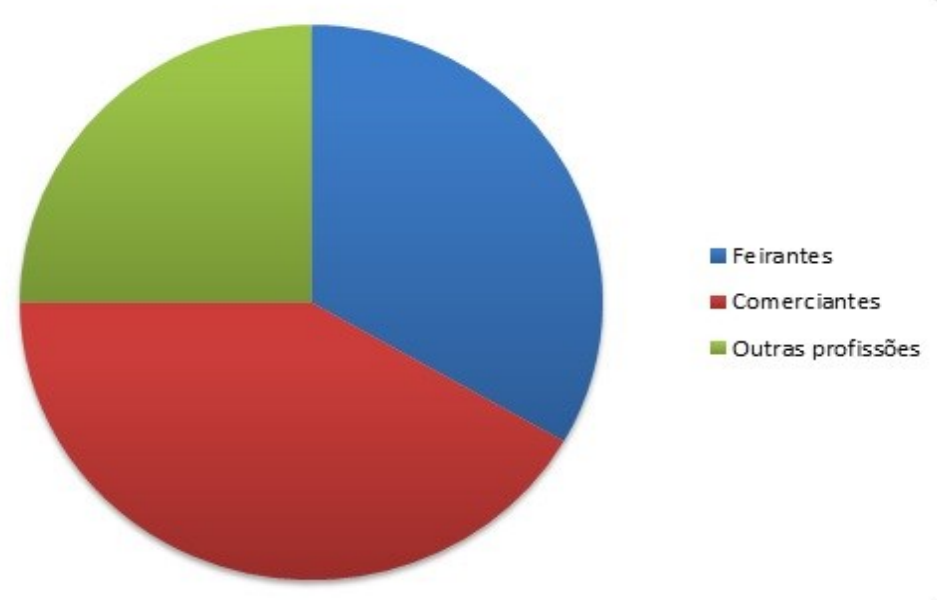

Além disso, nas entrevistas produzidas, tanto o pastor quanto a presidente da comunidade citam a importância deste fator na atuação da Nova Esperança em relação à prática religiosa: a maioria dos descendentes de alemães é proveniente das colônias do sul do Rio Grande do Sul e fizeram a transição da atividade rural em lavouras pra a atividade comerciária em Rio Grande.

A fim de compreender tal constatação, apresentamos a síntese de duas entrevistas realizadas com senhoras que fazem parte da Comunidade Nova Esperança, que migraram das colônias do sul para Rio Grande, considerando que o testemunho delas sobre o processo de migração da zona rural para o centro urbano permita uma análise sócio-histórica para a tendência ao comérico.

Destaca-se, dos relatos, a intencionalidade de ir para o centro urbano trabalhar nas feiras. De acordo com Balsan (2006), “A estrutura fundiária evolui em um sentido concentrador e excludente, dificultando, qualquer tipo de acesso à terra, aos trabalhadores rurais brasileiros" (p. 131.). Nesse processo, os testemunhos 
relatam que as famílias encontravam dificuldades em se manter no campo, pois plantavam como "sócias" em propriedades, onde parte da produção devia ser tributada ao dono da terra, e isso não permitia o desenvolvimento econômico dessas famílias. Acrescenta-se a isso, as transformações socioeconômicas do decorrer do século XX demarcam um período em que a sociedade de um modo geral estava se urbanizando e já em avançado processo de industrialização (BALSAN, 2006, p. 125), e a prática das trocas nas colônias já não supriam as necessidades cada vez mais numerosas das famílias.

Além dos problemas enfrentados nas colônias, as famílias vinham para Rio Grande atrás de experiências bem sucedidas de parentes que já estavam fixados na cidade trabalhando no comércio em feiras. Um dos relatos das senhoras foi de que, quando o esposo vinha à cidade trazer hortifrutigranjeiros para vender aos feirantes, ele já ia interessando-se e adaptando-se à prática do comércio. O outro relato é de que o esposo que antes era professor (mal remunerado), sempre teve mais interesse pelos negócios e, depois de casado e trabalhando no transporte de leite para a cidade, decidiu se estabelecer com a família em Rio Grande com o intuito direto de trabalhar no comércio.

As entrevistadas ainda falaram que a procura pelos estabelecimentos religiosos de vertente luterana foi automática na vida das suas famílias para a cidade do Rio Grande, já que era uma forma de manter suas tradições e conviver em um ambiente acolhedor, relatando que, na cidade, também tinham uma sensação de isolamento quanto aos seus hábitos culturais e religiosos, e a reunião nos cultos era uma forma de manter os laços com suas comunidades de origem.

\section{A ética protestante Luterana}

A proposta de se trabalhar com a comunidade Nova Esperança partiu da análise das construções teóri- cas de Max Weber em A Ética Protestante e o Espírito do Capitalismo. Neste estudo, o autor analisa a apropriação da conduta protestante pela lógica racionalista que o capitalismo usa para atingir o lucro. Este estudo de referência nos fez questionar a tendência à atividade econômica dos membros da comunidade através da influencia desse viés da conduta religiosa.

Pensando em alguns dos apontamentos que Weber levanta para explicar a preponderância protestante luterana nas atividades comerciárias em relação para a realidade contextualizada encontrada na Comunidade Luterana Nova Esperança e seus membros, a partir dos relatos orais utilizados, buscamos averiguar em quais aspectos a tendência identificada no questionário prévio possuem relação com a ética protestante discutida em Weber, resguardando algumas diferenciações apontadas por Bobsin (2005) entre a conduta luterana e calvinista.

Devemos salientar que este estudo tem seu foco na Nova Esperança, portanto, seu desenvolvimento e análise não necessariamente condizem diretamente com as conclusões que Weber apresenta em sua obra, até porque os contextos histórico e espacial são diferenciado e o foco de pesquisa de Weber é na vertente Calvinista. Entretanto, sua importância teórica nos estudos sobre Sociologia e Religião torna seu discurso essencial como referência na presente pesquisa, que procura entender as relações religiosas e econômicas no contexto específico da Igreja Evangélica de Confissão Luterana no Brasil (IECLB) em Rio Grande, em especial na Comunidade Nova Esperança.

O sociólogo Oneide Bobsin abre espaço para a discussão sobre a teoria de Weber e o Luteranismo nos dias atuais em um artigo publicado na Revista Eletrônica do Núcleo de Estudos e Pesquisa do Protestantismo (NEPP) em 2005. Em sua análise, Bobsin (2005) evidencia alguns argumentos da tese de Weber sobre a ética protestante e o espírito do capitalismo que demons- 
tram as variações entre a abordagem de Lutero e Calvino sobre a questão da vocação, e deixa em aberto as perspectivas de análise sobre essa questão na realidade atual.

Considerando nosso foco de análise, a Comunidade Nova Esperança, podemos trazer à discussão alguns questionamentos levantados por Bobsin que podem ser comparados com os dados obtidos na pesquisa empírica aqui presente. Observemos, especificamente, o seguinte trecho:

Outro contraste destacado por Weber mostra que a santificação da vida cotidiana nos marcos do calvinismo levava a um estilo metódico, como numa empresa (Weber, 2004, p. 13). Os luteranos, por sua vez, não seguiam por este caminho. "Agrassiaamissibilis luterana, que a todo instante podia ser recuperada pelo arrependimento, não continha em si, obviamente, nenhum estímulo àquilo que aqui nos importa como produto do protestantismo ascético: uma sistemática conformação racional da vida ética em seu conjunto" (BOBSIN, 2005, p. 13).

Aqui, o autor evidencia a distinção feita por Weber entre a conduta de trabalho do calvinismo e do luteranismo, e argumenta que a atividade econômica no luterano não possui sistematização racional, ou seja, exerce sua função tendo a superioridade da fé sobre a razão.

Para analisar os dados levantados na Comunidade Nova Esperança, trazemos à tona outro argumento de Weber, que aponta que uma das possibilidades que explicam o domínio de propriedades comerciais nas mãos de protestantes seria "pelo menos em parte, simplesmente como resultado da maior riqueza material herdada por eles" (WEBER, 2003, p. 39). Esse argumento pouco se aplica no caso dos membros da Nova Esperança, já que a maior parte da amostra pesquisada é composta por feirantes ou autônomos (observe o grá- fico 2), ou seja, não são proprietários de comércio, ainda dependem diretamente da produção agrícola para subsistirem ou são empregados.

\section{Gráfico 2 - Classificação da atividade profissional}

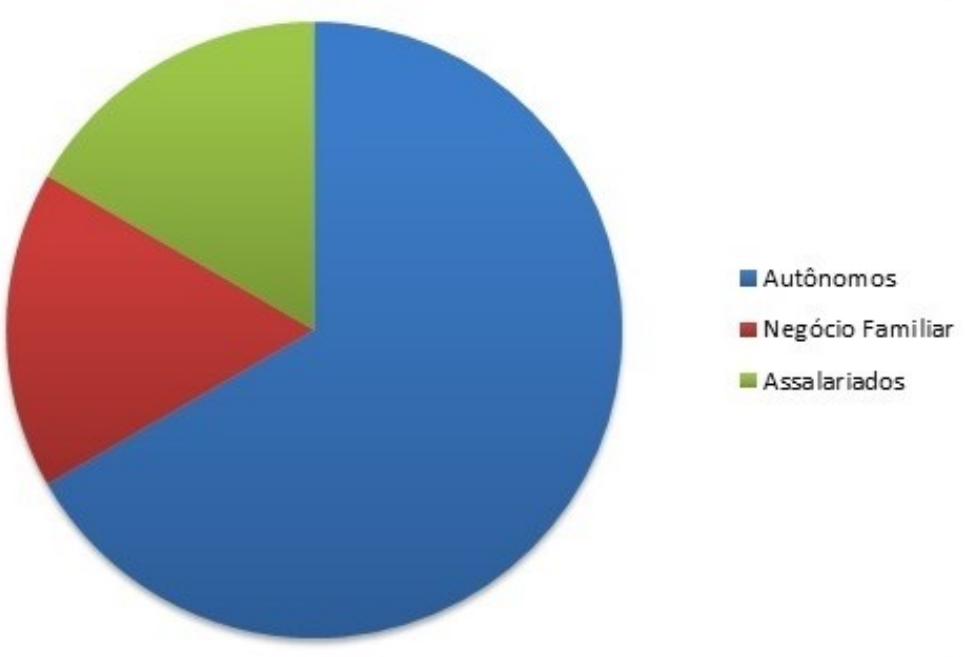

Nesse aspecto, a maior parte dos luteranos membros da Nova Esperança verificam a afirmação trazida por Bobsin à discussão, pois a maioria dos trabalhadores em questão exercem suas atividades econômicas em função de sua vocação ou conveniência conduzida pelas condições históricas impostas aos imigrantes e descendentes de alemães no Brasil e no Rio Grande do Sul. Podemos trazer como referencial histórico uma das afirmações de cunho religioso registrado em uma das duas entrevistas com senhoras membros da Nova Esperança, no seguinte relato: "Eu saí da lavoura direto para o comércio, meu esposo já saía, ia fazer trocas e venda na cidade. Isso tudo vem de Deus, era o que a gente conhecia, vem tudo que tu nem percebe."

Nesse trecho percebemos a função da religião no processo de transição do sistema agrário para o sistema urbano. Além disso, ambas as senhoras também trazem a questão como um processo natural, já que os esposos já trabalhavam com o transporte de produtos das colônias para serem vendidos nas feiras em Rio Grande. 
Ainda sobre os dados coletados nos questionários, $16,6 \%$ da amostra são proprietários de pequenos comércios que, nesse sentido, deve-se ao esforço da geração anterior saída das colônias de descendentes alemães do sul do Rio Grande do Sul, que transitaram entre a produção e a comercialização de produtos.

No contexto tratado ao longo da segunda metade do século XX, verifica-se a coexistência de uma racionalização do capitalismo (WEBER, 2003, p. 134), observada nas transformações profundas das relações de produção e comercialização de produtos (como a expansão das fronteiras agrícolas e comerciais), com uma dedicação irracional, ou puramente vocacional, ao trabalho, que contribuiria para que colonos expandissem sua atuação econômica para o âmbito do comércio em regiões mais urbanizadas (o que explica a vinda da geração mais antiga de membros da Comunidade para a cidade e a constituição da atuação no comercio de Rio Grande). O pastor Bonato também salienta como importante observação nesse movimento em direção às cidades, o aumento da população nas colônias e as práticas comunitárias que se tornavam cada vez menos viáveis no contexto da produção capitalista.

Ambas as senhoras entrevistadas que participam da Comunidade Nova Esperança, afirmam terem sido bem sucedidas na investida de suas famílias da zona rural e atividade agrária para a cidade de Rio Grande e a atividade comerciária. Os relatos trazem traços de religiosidade ao, ora afirmar que a transição da atividade produtiva foi um processo natural como desígnio de Deus, ora por considerarem-se agraciadas em suas preces pelas benesses geradas pelo trabalho.

Para evidenciar a importância da conduta religiosa nas atividades produtivas dos membros da Comunidade Nova Esperança, analisamos os documentos de fundação da comunidade e destacamos os seguintes tre- chos tratando das incumbências designadas a Comunidade Nova Esperança que endossam a discussão:

II - zelar para que seja dado testemunho do Evangelho em conformidade com a confissão da IECLB em doutrina, vida e ordem eclesiástica;

$\mathrm{V}$ - animar a cada um de seus membros a servir ao próximo no âmbito familiar, comunitário e público;

VII - congregar homens e mulheres com o fim de orientar todos os seus membros no cumprimento de suas tarefas específicas.

Destacam-se essas incumbências para que se possa trazer à discussão a valorização do outro e do sentido de comunidade abordados pelo pastor Bonato em entrevista. Parafraseando suas palavras, o sentido de comunidade está presente na cultura do alemão, e a grande herança que o luteranismo deixa para seus fiéis é o sentimento de comunidade vindo da interpretação do mandamento "amarás o senhor Teu Deus e amarás o próximo como a ti mesmo". O pastor ainda salienta que a função exercida na sociedade como atividade produtiva também é encarado pelo luterano em função do sentido de comunidade, tendo-se a consciência de que ao exercer seu trabalho com responsabilidade e eficiência, o cidadão fiel está contribuindo com o trabalho e vida do outro, da comunidade.

Sobre a importância da conduta protestante luterana no modo de se portar no trabalho, realizamos algumas discussões a partir do livro de Wolfgang Schweitzer intitulado Liberdade para Viver: questões fundamentais de ética, especificamente no capítulo “Trabalho e Propriedade" (1973, p. 105-146). O capítulo analisado trata do entendimento do trabalho na Bíblia e de como encarar na forma cristã as transformações vividas nas relações de produção no mundo moderno. O autor discute a função do operário industrial na divisão social do trabalho através do conceito de alienação desenvolvido por Marx: 
A consequência de tal alienação do trabalho natural foi, segundo Marx, entre outros, que o trabalhador se alienou de si mesmo; isso significa que ele não era capaz de entender corretamente sua humanidade. Não mais durante o trabalho, mas somente no tempo de lazer, o homem do presente se sente livre e humano. (SCHWEITZER, 1973, p. 113)

Enquanto contexto histórico, esta análise sobre a intensificação produtiva se faz importante em relação aos choques cultural e econômico vivenciados pelas comunidades agrárias na transição para a dinâmica urbana. A partir dessa perspectiva, como ressignificar a atividade produtiva pelo viés da religião?

Além disso, traz-se à tona a discussão sobre as novas rotinas de trabalho, que evidenciam a secularização da atividade produtiva, já que o sistema integrado não permite mais a todos, cristãos ou não, o descanso dos domingos. Nesse desenvolvimento da vida produtiva industrial e mecanizada, ao mesmo tempo em que muita da significação religiosa seja perdida, o trabalhador é cada vez mais exigido de sua responsabilidade e ética, ao respeitar seus horários, a dependência entre os trabalhadores e suas funções, e nesse sentido a conduta religiosa participa no modo como os luteranos em questão encaram o trabalho.

O autor atenta pelo perigo da "ideologização" do trabalho nas doutrinações religiosas, argumentando que a finalidade do trabalho pela fé em Cristo não é alcançar a salvação ou o sucesso pelo trabalho, mas sim buscar a solidariedade ao outro, ao próximo (1973, p. 118-119). Essa análise nos faz refletir sobre a maneira com que o luterano se insere na economia da sociedade capitalista: ele exerce sua função tendo em vista o funcionamento da sociedade em relação ao outro, tendo em vista a responsabilidade de sua atividade no sistema produtivo, composto por outras pessoas que merecem sua solidariedade como, crendo assim os cristãos, filhos de Deus: "E todo o nosso trabalho é, em última análise, colaboração com outros" (SCHWEITZER, 1973, p. 121).

Este aporte teórico coincide com os levantamentos feitos através das entrevistas com o pastor da IECLB e Comunidade Nova Esperança, além dos demais dados fornecidos em relação ao trabalho dos membros da Nova Esperança. Em sua fala, o pastor Bonato evidencia o mandamento "amarás o senhor teu Deus de todo teu coração, de toda a tua alma e amarás o teu próximo como a ti mesmo", valorizando sempre o princípio de colaboração e doação ao próximo em todas as atividades dos cristãos. Ele também reflete sobre a atuação dos cristãos na sociedade capitalista em que estamos atualmente inseridos. Adaptando de suas palavras, "a minha contribuição na comunidade econômica e material é justamente para que essa comunidade possa, dentro do sistema que nós vivemos, manter esse sistema".

\section{Conclusões}

Considerando que o principal objetivo do presente estudo foi analisar a relação entre os membros da Comunidade Luterana Nova Esperança e o trabalho, no caso, da atividade produtiva no comercio, considerando o viés da religiosidade, devemos relembrar alguns questionamentos trabalhados ao longo do texto.

A questão da vinda e o estabelecimento dos alemães no Brasil de um modo geral, e especificamente no sul do Rio Grande do Sul, não favoreceu a integração destes à dinâmica social e econômica do estado: a pouca infraestrutura encontrada, a falta de reconhecimento de seus hábitos e traços culturais, como o religioso, por exemplo, e outras discussões levantadas nos possibilitam avaliar que os imigrantes alemães e seus descendentes buscaram na religiosidade uma forma de se afirmarem como comunidade.

Ainda no aspecto da consolidação dos imigrantes no Rio Grande do Sul, tendo em vista alguns dos 
objetivos do governo brasileiro em estimular tal imigração, a atividade econômica à qual se dedicavam não poderia ser outra se não à prática agrícola, já que os espaços onde foram alocados careciam de infraestrutura. Além disso, as transformações econômicas e sociais que ocorreram desde a chegada dos primeiros imigrantes alemães, até a metade do século XX, afetaram diretamente o modo de vida e as atividades exercidas nas colônias de características agrárias, forçando os descendentes de alemães a procurarem novas formas de se sustentarem.

Podemos citar também como característico do perfil do luterano da Comunidade Nova Esperança o empenho ao trabalho, que pode ser confundido com a busca por retorno financeiro no sentido do acúmulo de riquezas. Entretanto, ao discutirmos a doutrina luterana e relacionando-a aos dados empíricos obtidos sobre o contexto da comunidade, percebemos uma relação importante entre o contexto histórico e a religiosidade valorizada com força pelos imigrantes alemães e seus descendentes nas colônias. Nesse sentido, a ética protestante colabora com a organização econômica vigente, mas a partir do seu sentido de comunidade, e não necessariamente no acúmulo de riquezas.

Para sintetizar a relação da religiosidade do luterano da Nova Esperança e sua atividade produtiva, o seguinte trecho de Schweitzer (1973) se faz esclarecedor:

Embora o agir do cristão não se distinga externamente daquilo que outros fazem, sua disposição para com o trabalho é basicamente alterada pela atitude básica antes mencionada. É claro que, aparentemente, não é mais possivel reavivar a antiga consciência vocacional dos cristãos em toda sua amplitude. Mais importante é que aprendamos a aceitar nosso mundo de hoje na fé. Então, certamente também aprenderíamos a crer que nosso trabalho se realiza a serviço dos outros mesmo quando há muito que nos parece absurdo. (p. 123)

Essas observações nos possibilitam avaliar que as atividades econômicas exercidas pelos descendentes membros da Comunidade Nova Esperança são consequência da sua condição de isolamento vivenciada na constituição das colônias alemãs no Rio Grande do Sul, que reforçaram seus laços com a doutrina do protestantismo luterano, somada a um contexto de desenvolvimento peculiar do século XX que amplia e racionaliza as relações econômicas e alteram a dinâmica de relação entre o luterano e o trabalho.

Percebemos a importância da religiosidade na comunidade em questão mais relacionada com contexto histórico vivido no Rio Grande do Sul do que com a intencionalidade lucrativa característica do espírito capitalista, e nos coube, neste artigo, discutir o caminho entre a atividade agrária nas colônias do sul do estado para a atividade comerciária em Rio Grande, observando as peculiaridades da trajetória dos descendentes alemães no Rio Grande do Sul, particularmente a dos membros da comunidade luterana Nova Esperança, considerando a questão religiosa como fator essencial na construção da unidade e fortalecimento da noção de comunidade. 


\section{Referências}

BALSAN, R. Impactos decorrentes da modernização da agricultura brasileira. Campo-território: revista da geografia agrária, vol. 1, n², p. 123-151, agosto de 2006.

BOBSIN, O. Luteranos na Ética Protestante. Revista Eletrônica do Núcleo de Estudos e Pesquisa d Protestantismo (NEEP) da Escola Superior de Teologia. Vol. 06, Jan-Abr de 2005.

CAPES <www.capes.gov.br $>$ Acessado em 06/05/2014.

GERTZ, René E. . Os luteranos no Brasil. Revista de História Regional. Ponta Grossa, v. 6, n.2, p. 9-33, 2001.

HEINZ, W. P. P.. A presença dos imigrantes alemães e sua contribuição para a economia e a cultura na cidade do Rio Grande (1824/1950). 1º. ed. Pelotas: Editora Universitária/UFPEL, 2010. 124p .

MEIHY, J.C.S.B. Guia prático de história oral: para empresas, universidades, comunidades, famílias. São Paulo: Contexto, 2011.

PORTAL LUTERANOS. Disponivel em: <www.luteranos.com.br> Acessado em 06 maio 2014.

PORTO DO RIO GRANDE. Disponível em: <www.portoriogrande.com.br> Acessado em 20 ago. 2013

SALAMONI, G. A imigração alemã no Rio Grande do Sul - o caso da comunidade pomerana de Pelotas. História em Revista (UFPel), v. 7, p. 25-42, 2001.

SALLES, Iraci Galvão. Trabalho, progresso e a sociedade civilizada. Hucitec. São Paulo, 1986

SCHWEITZER, W. Liberdade para viver: questões fundamentais da ética. São Leopoldo: Editora Sinodal, 1973.

SILVA, A. C. da . Branqueamento e branquitude: conceitos básicos na formação para a alteridade. In: Antônio Dias Nascimento; Tânia Maria Hetkowski. (Org.). Memória e formação de professores. 1ed. Salvador: EDUFBA, 2007, v. 01.

VITAL JUNIOR, R. R. Caminhos da Colonização Alemã no Rio Grande do Sul: políticas de estado, etnicidade e transição. In: CARELI, S. da S. KNIERIM, L. C. (orgs). Releituras da história do Rio Grande do Sul. Porto Alegre: CORAG, 2008.

WEBER, M. A ética protestante e o espírito do capitalismo. Tradução de Pietro Nasseitti. São Paulo: Martin Claret, 2003.

Submissão: 12/05/2017

Aceite: 25/03/2018 